\title{
Efeito do protocolo de exercício sobre variáveis hematológicas e bioquímicas em eqüinos de salto*
}

\author{
VALESCA PETER DOS SANTOS
}

\author{
Félix Hilário Diaz González (Orientador - UFRGS)
}

Banca: Carlos Eduardo Wayne Nogueira (UFPel), Flavio de la Corte (UFSM), Petra Garbade (UFRGS)

O presente estudo teve por objetivo avaliar as variações provocadas por diferentes protocolos de atividade física nos parâmetros hemato-bioquímicos de eqüinos de salto. Foram utilizados dezessete eqüinos atletas, de raças de hipismo, com idades variando entre 5 e 12 anos. Todos os animais fizeram parte de três grupos de exercício e um de repouso. Foram realizadas coletas de sangue venoso e verificação da freqüência cardíaca com os animais em repouso (grupo Controle) e imediatamente após a realização de três diferentes protocolos de exercício. Os animais foram submetidos a 20 e 40 minutos de exercício em esteira com inclinação de $0^{\circ}$ a velocidade constante de $5 \mathrm{~m} / \mathrm{s}$ (grupo Esteira), 40 minutos de trabalho montado sendo 10 minutos ao passo, 20 minutos de trote e 10 minutos de galope em pista plana de areia (grupo treinamento) e prova de salto à velocidade média de $350 \mathrm{~m} / \mathrm{min}$, altura dos obstáculos de 1,20 metros e extensão do percurso de 430 metros (grupo Prova). Os parâmetros hematológicos (número de eritrócitos, concentração de hemoglobina e contagem leucocitária), a frequiência cardíaca, dosagem das enzimas creatina quinase (CK), aspartato aminotransferase (AST), lactato desidrogenase (LDH) e fosfatase alcalina (FA), dosagem de sódio e potássio, bicarbonato, proteínas plasmáticas totais, uréia e creatinina foram analisados. Os valores obtidos foram comparados com os valores basais e entre os grupos de exercício. O exercício em Esteira provocou aumento significativo no percentual de hematócrito e concentração de creatinina. A concentração de glicose apresentou redução após 20 e 40 minutos de exercício. O grupo Treinamento revelou aumento no número de eritrócitos, aumento de hematócrito, proteínas totais, CK, LDH, FA, creatinina, potássio e redução nas concentrações de glicose. O grupo Prova apresentou contagem de eritrócitos superior aos demais grupos, assim como percentual de hematócrito, concentração de hemoglobina e proteínas plasmáticas totais. Nesse grupo, as dosagens de CK, LDH, FA, lactato, creatinina e potássio apresentaram valores significativamente superiores em relação ao grupo Controle. A frequiência cardíaca revelou aumento significativo após a realização da atividade física quando comparados com o grupo Controle e entre os grupos. As variações encontradas foram de amplitude maior no grupo Prova. O aumento da intensidade do exercício físico provoca alterações em alguns parâmetros hemato-bioquímicas em cavalos de salto. A contagem eritrocitária, o percentual de hematócrito, a concentração de proteínas plasmáticas, lactato, potássio, creatinina, CK e FA elevam-se com o aumento da intensidade do exercício. A contagem leucocitária, dosagem de AST, sódio, bicarbonato e uréia não sofreram influência da intensidade de exercício proposta nos protocolos. A concentração de glicose é reduzida pelo exercício desempenhado nos grupos treinamento e prova.

Descritores: exercício, esteira, eqüinos, hematologia, treinamento, bioquímica.

Apresentada: 17 janeiro 2006

"Dissertação de Mestrado n. 417 (Especialidade: Patologia Animal). 94f. Programa de Pós-graduação em Ciências Veterinárias [www.ufrgs.br/ ppgcv], Faculdade de Veterinária, Universidade Federal do Rio Grande do Sul (UFRGS), Porto Alegre-RS. CORRESPONDÊNCIA: V.P. Santos [valescapsantos@hotmail.com] \& F.H.D. González [felixgon@ufrgs.br]. 


\title{
Effect of exercise protocols on haemathologic and biochemistry parameters in jumping horses ${ }^{* *}$
}

\author{
VALESCA PETER DOS SANTOS
}

\author{
Félix Hilário Diaz González (Adviser - UFRGS)
}

Committee: Carlos Eduardo Wayne Nogueira (UFPel), Flavio de la Corte (UFSM), Petra Garbade (UFRGS)

The aim of this study was to evaluate the effect of different exercise protocols on haemathologic and biochemistry parameters in jumping horses. Seventeen Brazilian Jumping adult horses, aged from 5 to 12 years were used in this study. They were exeamined in rest and exercised according to 3 protocols designed. Venous blood samples were drawn from the jugular vein and heart rate were verified at rest (Control group) and after the 3 protocols of exercise. The animals walked on a treadmill at $0^{\circ}$ incline during 40 minutes at a speed of $5 \mathrm{~m} / \mathrm{s}$ (Treadmill group), trained for 40 minutes consisting at 10 minutes of walk, 20 minutes of trot and 10 minutes of gallop on field conditions (Training group) and jumped in a Jumping Competition, speed of $350 \mathrm{~m} / \mathrm{min}$, height of obstacles 1,20 m and $430 \mathrm{~m}$ lenght (Jump group). The haemathological parameters (erythrocytes, packed cell volume, hemoglobin, leucocytes), creatine phosphokinase (CK), aspartate amino transferase (AST), lactate dehydrogenase (LDH), alkaline phosphatase, sodium, potassium, bicarbonate, total plasma protein, urea, creatinine were analysed before and after exercise. The Treadmill group showed an increase in packed cell volume and creatinine concentration. Training group showed elevations in number of erythrocytes, packed cell volume, total plasma protein, CK, LDH, alkaline phosphatase, creatinine, potassium. Jump group promoted an increase of erythrocytes, hemoglobin, total plasma protein, CK, LDH, alkaline phosphatase, lactate, creatinine, potassium. Glucose concentration was decreased according to the exercise protocols. Heart rate increased as the exercise intensity increased. All variations detected were highest in Jump group. The physical exercise intensity changes some hematological and biochemical parameters of jumpers.

Key words: exercise, treadmill, horses, haemathology, training, biochemistry.

\footnotetext{
***Master's Thesis \#417 (Field: Veterinary Pathology). 94p. Graduate Program in Veterinary Sciences [www.ufrgs.br/ppgcv], Faculdade de Veterinária, Universidade Federal do Rio Grande do Sul (UFRGS), Porto Alegre/Brazil. CORRESPONDENCE: V.P. Santos [valescapsantos@ hotmail.com] \& F.H.D. González [felixgon@ufrgs.br].
} 